\title{
Scholarly Impact of Academic Ophthalmologists and Vision Scientists in Canada
}

\author{
Michael T Kryshtalskyj (DI \\ Matthew J Novello ${ }^{2}$ \\ Monali S Malvankar- \\ Mehta $(\mathbb{D})^{3,4}$ \\ Marcelo T Nicolela ${ }^{5}$ \\ Cindy ML Hutnik ${ }^{3,6}$ \\ 'Department of Surgery (Section of \\ Ophthalmology), University of Calgary, \\ Calgary, Alberta, Canada; ${ }^{2}$ Department \\ of Physiology and Pharmacology, Western \\ University, London, Ontario, Canada; \\ ${ }^{3}$ Department of Ophthalmology, \\ Western University, London, Ontario, \\ Canada; ${ }^{4}$ Department of Epidemiology \\ and Biostatistics, Western University, \\ London, Ontario, Canada; ${ }^{5}$ Department \\ of Ophthalmology and Visual Sciences, \\ Dalhousie University, Halifax, Nova \\ Scotia, Canada; ${ }^{6}$ Department of \\ Pathology, Western University, London, \\ Ontario, Canada
}

Objective: To outline the current impact of Canadian ophthalmology and vision science research as measured by novel research metrics.

Design: Cross-sectional survey.

Participants: All Canadian ophthalmologists $(n=687)$ and vision scientists $(n=119)$ with an online bibliometric profile and academic appointment at a major ophthalmology training centre were included.

Methods: Faculty lists of Canada's 15 major academic ophthalmology departments were obtained. Faculty names, appointments, sex, and educational background were recorded. Elsevier's Scopus database was used to calculate H-index, m-quotient, and total citations for each faculty member. Details around grant funding were obtained through the Canadian Institutes of Health Research (CIHR) Funding Decisions Database.

Results: Average H-indices were $7.42 \pm 7.98$ for ophthalmologists and $23.78 \pm 15.25$ for vision scientists. Higher academic appointment was correlated with higher h-indices and m-quotients ( $\mathrm{p}<0.0001$ for both). Most academic departments had significantly more males than females (avg. 71\% male, 29\% female); however, more equal ratios were seen in faculties in Quebec. No significant differences in research impact were identified between male and female ophthalmologists when controlled for academic appointment and career stage $(p>0.05)$. In clinical ophthalmology research, the top three departments with the highest average $\mathrm{H}$-indices were Western University, the University of Toronto, and Dalhousie University. The University of British Columbia, Université de Montréal, and McGill University received the most funding from the CIHR in the last 10 years.

Conclusion: This study highlights the current scope of ophthalmology and vision science research in Canada. Important trends were identified in research productivity across academic rank, sex, and clinical subspecialty.

Keywords: bibliometrics, h-index, m-quotient, scholarly impact, research, ophthalmology

\section{Introduction}

Canada's 15 academic ophthalmology departments serve numerous roles, including generating and disseminating new knowledge through research. Research in academic departments helps refine clinical practice, encourage analytical approaches in trainees, secure grant funding, promote career development and foster educational partnerships. $^{1-4}$

With an ever-changing academic landscape and resource availability in Canadian ophthalmology departments, it is important to objectively assess the impact of research in contemporary terms. Two studies published in 2009 and 2010 have previously evaluated the research impact of Canadian ophthalmology departments. ${ }^{5,6}$ These
Correspondence: Michael T Kryshtalskyj Department of Surgery (Section of Ophthalmology), University of Calgary, Eye Clinic, Rockyview General Hospital, Main (Fourth) Floor, Fisher Building, 7007 14th Street SW, Calgary, T2VIP9,

Alberta, Canada

Tel + I-(647)-938-4450

Email michael.kryshtalskyj@ucalgary.ca 
studies gauged institutional research impact primarily using total number of papers, citations, and the total number of papers that departments published in top ophthalmology journals. However, there are several limitations to these metrics. The number of papers, for instance, does not account for their ultimate influence. The number of citations does not give insight towards an author's consistency of publishing high impact studies over time. Further, the average career stage of institutional faculty is also a significant confounding factor not accounted for in this methodology, as newly graduated staff typically have less output compared to established, tenured faculty. Relying upon the number of articles published in clinical ophthalmology journals also omits important non-clinical research done by Canadian vision science programs, including basic and translational science research.

Recently, new research metrics have emerged that offer a more comprehensive assessment of research impact. The h-index has become widely accepted in academia due to its ability to account for both publication quantity and quality through citation count. ${ }^{7}$ Mathematically, the h-index is defined by the number of an author's publications, $h$, that have been cited at least $h$ times in the peer-reviewed literature. ${ }^{8}$ Thus, the h-index prioritizes frequently cited publications over the volume of papers in assessing an author's impact. Another measure, the m-quotient, helps control for the career stage of a researcher by dividing an author's h-index by the number of years since their first publication. ${ }^{8}$ In the ophthalmology literature, the h-index has been related to national research productivity, ${ }^{9,10}$ National Institutes of Health (NIH) funding, ${ }^{1}$ the academic impact of chairs and fellowship-trained ophthalmologists, ${ }^{11,12}$ and sex differences among American ophthalmology departments. ${ }^{13,14}$

This study aims to assess a number of questions around the current state of ophthalmology research in Canada: a) what is the scholarly impact of ophthalmology and vision science faculty members at academic Canadian centres, stratifying by institution, sex, academic appointment, ophthalmologic subspecialty, and educational background; b) what is the correlation of research impact to the size of grants received by the Canadian Institutes for Health Research (CIHR).

\section{Methods}

\section{Demographic Data}

Faculty lists of all 15 Canadian academic ophthalmology departments offering residency training programs were obtained from departmental websites. These lists were used to obtain the names, appointments, sex, degrees (MD and/or PhD) and subspecialties of each faculty member. While there was some heterogeneity around the titles of appointments from university to university, equivalent appointments were sorted into 3 groups: Assistant Professors (including lower ranks, such as lecturers and non-professorial associates and assistants), Associate Professors and (Full) Professors. Past and present Chairs of departments were also identified. Where departmental websites were last updated before January 1, 2020, or did not include these full details, the department was contacted directly.

\section{Clinical Subspecialties}

Subspecialties were chiefly categorized according to the major areas of clinical focus recognized at the Annual Meetings of the Canadian Ophthalmological Society: comprehensive ophthalmology/cataract surgery; cornea, external disease and refractive surgery; glaucoma; neuroophthalmology; oculoplastic and reconstructive surgery; ophthalmic pathology; paediatric ophthalmology and strabismus; retina (medical and surgical); uveitis; and vision rehabilitation. Ocular genetics and ocular oncology were also included. Subspecialties were documented for academic ophthalmologists only when they had completed a formal fellowship in that field, except vision rehabilitation. Faculty who had completed fellowships in two or more clinical areas were counted in the subgroup analyses of each of the subspecialties they trained in.

\section{Vision Scientists}

Vision scientists were defined as any faculty member engaging in ophthalmology or vision-related basic science and lab bench research. Basic science was defined as any abstract conducted in the realms of neuro-visual pathways, visual psychology, neuroscience and neurodevelopment, electrophysiology, cellular and molecular biology, pathobiology, pharmacology, genetics, chemistry, optics, biophysics, and bioengineering. Clinical ophthalmologists were dually counted as vision scientists if they also engaged in this form of research. Faculty lists often include cross-appointed, non-ophthalmologist MDs (eg, pathologists, neurologists, neurosurgeons, and plastic surgeons), non-PhD researchers, and other professionals (eg, optometrists and orthoptists) supporting ophthalmologyrelated research. These faculty members were included in a separate subgroup of vision scientists in consideration of 
Table I Bibliometric Profiles of Ophthalmology and Vision Science Faculty in Canada

\begin{tabular}{|c|c|c|c|c|}
\hline & Sample (n) & H-index (Mean \pm SD) & m-quotient (Mean \pm SD) & Citations (Mean \pm SD) \\
\hline \multicolumn{5}{|l|}{ Summary } \\
\hline Ophthalmologists & 686 & $7.40 \pm 7.98$ & $0.35 \pm 0.29$ & $526.03 \pm 1308.64$ \\
\hline Basic Scientists & 119 & $23.78 \pm 15.25$ & $0.84 \pm 0.43$ & $2960.38 \pm 4676.30$ \\
\hline Affiliated Clinicians* & 31 & $22.13 \pm 21.68$ & $0.83 \pm 0.62$ & $3629.42 \pm 7997.19$ \\
\hline \multicolumn{5}{|c|}{ Clinical Ophthalmologists } \\
\hline \multicolumn{5}{|l|}{ Sex } \\
\hline Male & 496 & $7.89 \pm 8.01$ & $0.35 \pm 0.29$ & $571.07 \pm 1304.07$ \\
\hline Female & 190 & $6.21 \pm 7.78$ & $0.36 \pm 0.28$ & $413.97 \pm 1322.94$ \\
\hline \multicolumn{5}{|l|}{ Degree } \\
\hline MD & 658 & $6.95 \pm 7.51$ & $0.33 \pm 0.28$ & $472.94 \pm \mid 242.81$ \\
\hline $\mathrm{MD} / \mathrm{PhD}$ & 30 & $17.33 \pm 11.13$ & $0.67 \pm 0.31$ & $1690.67 \pm 2027.18$ \\
\hline \multicolumn{5}{|l|}{ Academic Appointment } \\
\hline Assistant Professor & 462 & $4.91 \pm 4.61$ & $0.30 \pm 0.26$ & $254.92 \pm 750.92$ \\
\hline Associate Professor & 127 & $9.03 \pm 6.37$ & $0.38 \pm 0.26$ & $562.63 \pm 976.44$ \\
\hline Professor & 97 & $17.26 \pm 12.94$ & $0.54 \pm 0.38$ & $1780.22 \pm 2519.04$ \\
\hline Chair & 28 & $17.14 \pm 10.76$ & $0.58 \pm 0.32$ & $1585.86 \pm 1745.28$ \\
\hline \multicolumn{5}{|l|}{ Fellowship Training } \\
\hline No fellowship & 176 & $3.81 \pm 4.05$ & $0.21 \pm 0.23$ & $140.24 \pm 262.80$ \\
\hline I Fellowship & 466 & $8.17 \pm 7.83$ & $0.39 \pm 0.28$ & $595.48 \pm 1345.98$ \\
\hline$\geq 2$ Fellowships & 46 & $13.81 \pm 13.94$ & $0.51 \pm 0.40$ & $1397.10 \pm 2539.06$ \\
\hline \multicolumn{5}{|l|}{ Subspecialty } \\
\hline Comprehensive & 176 & $3.85 \pm 4.11$ & $0.22 \pm 0.23$ & $14 \mid .48 \pm 262.92$ \\
\hline Retina & 123 & $8.49 \pm 6.90$ & $0.42 \pm 0.31$ & $817.24 \pm 1670.69$ \\
\hline Cornea & 95 & $7.76 \pm 7.15$ & $0.33 \pm 0.26$ & $437.43 \pm 778.76$ \\
\hline Glaucoma & 95 & $9.44 \pm 11.52$ & $0.42 \pm 0.37$ & $869.14 \pm 1975.28$ \\
\hline Paediatric Ophth/Strab & 72 & $9.89 \pm 11.08$ & $0.42 \pm 0.32$ & $808.54 \pm 1956.56$ \\
\hline Oculoplastics & 57 & $8.32 \pm 7.93$ & $0.34 \pm 0.21$ & $459.90 \pm 1018.18$ \\
\hline Neuro-Ophthalmology & 40 & $8.87 \pm 8.28$ & $0.46 \pm 0.28$ & $531.28 \pm 886.64$ \\
\hline Uveitis & 29 & $8.55 \pm 6.98$ & $0.41 \pm 0.23$ & $510.66 \pm 917.15$ \\
\hline Ocular Oncology & 19 & $15.13 \pm 17.38$ & $0.51 \pm 0.33$ & $1787.13 \pm 3893.77$ \\
\hline Ocular Genetics & 9 & $24.10 \pm 15.24$ & $0.87 \pm 0.49$ & $2775.73 \pm 3056.45$ \\
\hline Ocular Pathology & 9 & $10.22 \pm 10.21$ & $0.35 \pm 0.24$ & $791.00 \pm 1359.95$ \\
\hline Low vision & 9 & $4.78 \pm 4.79$ & $0.30 \pm 0.22$ & $157.67 \pm 299.92$ \\
\hline \multicolumn{5}{|l|}{ Vision Science } \\
\hline \multicolumn{5}{|l|}{ Sex } \\
\hline Male & 76 & $24.87 \pm 16.71$ & $0.83 \pm 0.44$ & $3301.00 \pm 5458.15$ \\
\hline Female & 43 & $21.86 \pm 12.22$ & $0.86 \pm 0.40$ & $2358.35 \pm 2767.31$ \\
\hline \multicolumn{5}{|l|}{ Degree } \\
\hline MD & 9 & $20.22 \pm 13.72$ & $0.72 \pm 0.44$ & $2214.11 \pm 3188.98$ \\
\hline $\mathrm{MD} / \mathrm{PhD}$ & 7 & $22.14 \pm 7.63$ & $0.83 \pm 0.24$ & $1851.57 \pm 1173.53$ \\
\hline $\mathrm{PhD}$ & 78 & $24.35 \pm|2.4|$ & $0.86 \pm 0.37$ & $2748.88 \pm 2699.80$ \\
\hline \multicolumn{5}{|l|}{ Academic Appointment } \\
\hline Assistant Professor & 45 & $14.70 \pm 9.64$ & $0.66 \pm 0.41$ & $1160.57 \pm 1326.05$ \\
\hline Associate Professor & 22 & $18.82 \pm 6.70$ & $0.82 \pm 0.32$ & $1854.27 \pm 1439.57$ \\
\hline Professor & 53 & $33.38 \pm 16.09$ & $1.00 \pm 0.43$ & $4913.70 \pm 6339.13$ \\
\hline
\end{tabular}

Notes: *Affiliated Clinicians included non-ophthalmologist MDs, non-PhD researchers, and other professionals (eg optometrists and orthoptists), included in the Vision Scientists analysis. 


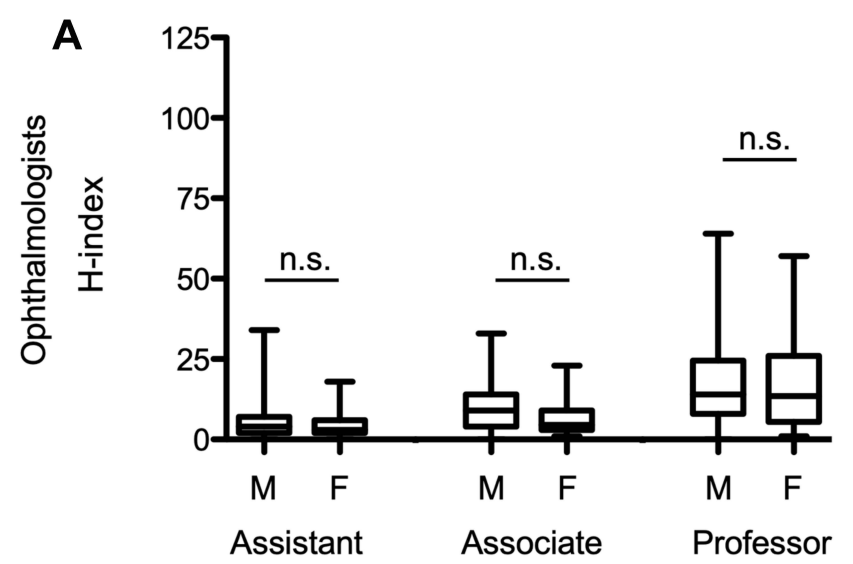

\section{B}

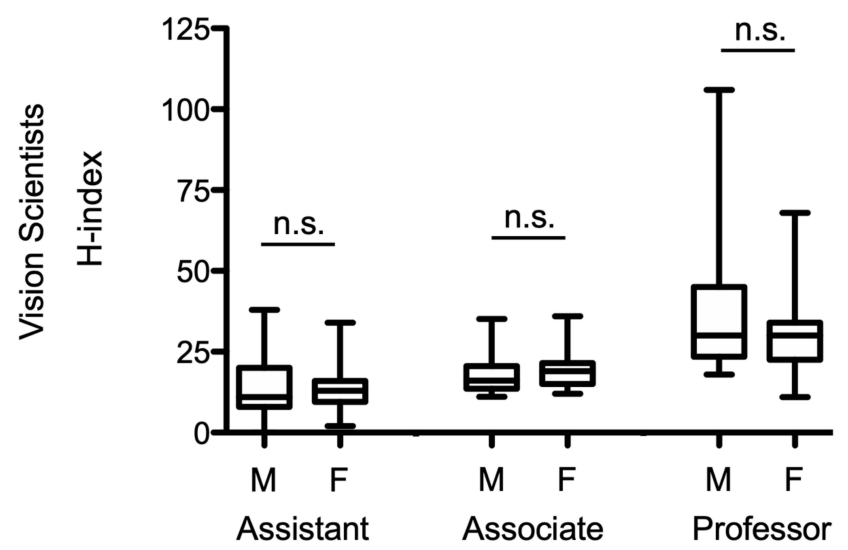

Figure I Average $\mathrm{H}$-indices for ophthalmologists (A) and vision scientists (B) stratified by sex and rank.

the intellectual, physical, and financial resources they often bring to ophthalmology and vision science programs.

\section{Research Metrics}

Elsevier's Scopus database (www.scopus.com, accessed July 24, 2020) was used to calculate and obtain research metrics for every Canadian academic ophthalmologist and vision scientist. Metrics included H-index, m-quotient, first year of publication and the total number of citations. Self-citations were excluded when tabulating $\mathrm{H}$-index and total citations. When a researcher's profile could not be easily identified in Scopus, two authors (MK, MN) crosschecked two other databases (PubMed and Google Scholar) in an effort to locate that faculty member's online research profile. Data collection began in March 2020 and was completed in July 2020.

\section{Funding Data}

Federal grants awarded to Canadian academic ophthalmologists and vision scientists from 2008 to 2020 were obtained
Table 2 Sex Distribution of Clinical Ophthalmologists and Vision Scientists with Bibliometric Profiles Appointed at Accredited Canadian Academic Institutions

\begin{tabular}{|c|c|c|c|}
\hline & $\begin{array}{l}\text { Clinical } \\
\text { Ophthalmologists }\end{array}$ & $\begin{array}{l}\text { Vision } \\
\text { Scientists }\end{array}$ & Total \\
\hline Total & $n=686$ & $n=119$ & $\mathrm{n}=793$ \\
\hline Male (\%) & 496 (72\%) & 76 (64\%) & $566(71 \%)$ \\
\hline Female (\%) & $190(28 \%)$ & 43 (36\%) & 227 (29\%) \\
\hline Assistant & $n=462$ & $n=45$ & $\mathrm{n}=505$ \\
\hline Male (\%) & $320(69 \%)$ & $28(62 \%)$ & 347 (69\%) \\
\hline Female (\%) & 142 (31\%) & 17 (38\%) & $158(31 \%)$ \\
\hline Associate & $n=127$ & $n=22$ & $n=147$ \\
\hline Male (\%) & 99 (78\%) & 13 (59\%) & 112 (76\%) \\
\hline Female (\%) & $28(22 \%)$ & $9(41 \%)$ & 35 (24\%) \\
\hline Professor & $n=97$ & $\mathrm{n}=53$ & $n=141$ \\
\hline Male (\%) & 77 (79\%) & $28(53 \%)$ & 107 (76\%) \\
\hline Female (\%) & $20(21 \%)$ & 17 (32\%) & 34 (24\%) \\
\hline Chair & $n=28$ & - & $\mathrm{n}=28$ \\
\hline Male (\%) & $24(86 \%)$ & - & $24(86 \%)$ \\
\hline Female (\%) & $4(14 \%)$ & - & $4(14 \%)$ \\
\hline Université Laval & $n=29$ & $\mathrm{n}=10$ & $n=37$ \\
\hline Male (\%) & 14 (48\%) & $6(60 \%)$ & $19(51 \%)$ \\
\hline Female (\%) & $15(52 \%)$ & $4(40 \%)$ & 18 (49\%) \\
\hline Université & $n=75$ & $n=13$ & $\mathrm{n}=86$ \\
\hline de Montréal & & & \\
\hline Male (\%) & 37 (49\%) & $8(62 \%)$ & 45 (52\%) \\
\hline Female (\%) & 38 (5।\%) & $5(38 \%)$ & 41 (48\%) \\
\hline University of & $\mathrm{n}=11$ & - & $\mathrm{n}=11$ \\
\hline Saskatchewan & & & \\
\hline Male (\%) & 7 (64\%) & & 7 (64\%) \\
\hline Female (\%) & $4(36 \%)$ & & $4(36 \%)$ \\
\hline Université de & $n=12$ & $n=1$ & $n=13$ \\
\hline Sherbrooke & & & \\
\hline Male (\%) & $8(67 \%)$ & I (100\%) & $9(69 \%)$ \\
\hline Female (\%) & $4(33 \%)$ & 0 & $4(31 \%)$ \\
\hline University of & $\mathrm{n}=152$ & $n=33$ & $\mathrm{n}=183$ \\
\hline Toronto & & & \\
\hline Male (\%) & 112 (74\%) & $19(58 \%)$ & $|3|(72 \%)$ \\
\hline Female (\%) & $40(26 \%)$ & $14(42 \%)$ & $52(28 \%)$ \\
\hline McGill University & $n=45$ & $\mathrm{n}=11$ & $\mathrm{n}=56$ \\
\hline Male (\%) & $33(73 \%)$ & 8 (73\%) & $4 \mathrm{l}(73 \%)$ \\
\hline Female (\%) & $12(27 \%)$ & $3(27 \%)$ & $15(27 \%)$ \\
\hline McMaster University & $n=22$ & - & $\mathrm{n}=22$ \\
\hline Male (\%) & $16(73 \%)$ & & $16(73 \%)$ \\
\hline Female (\%) & $6(27 \%)$ & & $6(27 \%)$ \\
\hline University of British & $n=103$ & $n=19$ & $n=120$ \\
\hline Columbia & & & \\
\hline Male (\%) & 78 (76\%) & $12(63 \%)$ & $88(73 \%)$ \\
\hline Female (\%) & $25(24 \%)$ & 7 (37\%) & $32(27 \%)$ \\
\hline
\end{tabular}

(Continued) 
Table 2 (Continued).

\begin{tabular}{|c|c|c|c|}
\hline & $\begin{array}{l}\text { Clinical } \\
\text { Ophthalmologists }\end{array}$ & $\begin{array}{l}\text { Vision } \\
\text { Scientists }\end{array}$ & Total \\
\hline $\begin{array}{l}\text { Western University } \\
\text { Male (\%) } \\
\text { Female (\%) }\end{array}$ & $\begin{array}{l}n=20 \\
15(75 \%) \\
5(25 \%)\end{array}$ & $\begin{array}{l}n=5 \\
3(60 \%) \\
2(40 \%)\end{array}$ & $\begin{array}{l}n=23 \\
17(74 \%) \\
6(26 \%)\end{array}$ \\
\hline $\begin{array}{l}\text { Queen's University } \\
\text { Male (\%) } \\
\text { Female (\%) }\end{array}$ & $\begin{array}{l}n=20 \\
15(75 \%) \\
5(25 \%)\end{array}$ & - & $\begin{array}{l}n=20 \\
15(75 \%) \\
5(25 \%)\end{array}$ \\
\hline $\begin{array}{l}\text { University of } \\
\text { Alberta } \\
\text { Male (\%) } \\
\text { Female (\%) }\end{array}$ & $\begin{array}{l}n=25 \\
16(60 \%) \\
9(40 \%)\end{array}$ & $\begin{array}{l}n=4 \\
4(100 \%) \\
0\end{array}$ & $\begin{array}{l}\mathrm{n}=45 \\
34(76 \%) \\
\mathrm{II}(24 \%)\end{array}$ \\
\hline $\begin{array}{l}\text { University of } \\
\text { Calgary } \\
\text { Male (\%) } \\
\text { Female (\%) }\end{array}$ & $\begin{array}{l}n=36 \\
29(81 \%) \\
7(19 \%)\end{array}$ & $\begin{array}{l}n=5 \\
3(60 \%) \\
2(40 \%)\end{array}$ & $\begin{array}{l}n=43 \\
33(77 \%) \\
10(33 \%)\end{array}$ \\
\hline $\begin{array}{l}\text { University of } \\
\text { Ottawa } \\
\text { Male (\%) } \\
\text { Female (\%) }\end{array}$ & $\begin{array}{l}n=48 \\
39(81 \%) \\
9(19 \%)\end{array}$ & $\begin{array}{l}n=6 \\
4(67 \%) \\
2(33 \%)\end{array}$ & $\begin{array}{l}n=53 \\
42(79 \%) \\
11(21 \%)\end{array}$ \\
\hline $\begin{array}{l}\text { University of } \\
\text { Manitoba } \\
\text { Male (\%) } \\
\text { Female (\%) }\end{array}$ & $\begin{array}{l}n=28 \\
23(82 \%) \\
5(18 \%)\end{array}$ & - & $\begin{array}{l}n=28 \\
23(82 \%) \\
5(18 \%)\end{array}$ \\
\hline $\begin{array}{l}\text { Dalhousie } \\
\text { University } \\
\text { Male (\%) } \\
\text { Female (\%) }\end{array}$ & $\begin{array}{l}n=32 \\
28(88 \%) \\
4(12 \%)\end{array}$ & $\begin{array}{l}n=13 \\
9(69 \%) \\
4(31) \%\end{array}$ & $\begin{array}{l}n=41 \\
35(85 \%) \\
6(15 \%)\end{array}$ \\
\hline
\end{tabular}

through the Canadian Institutes of Health Research (CIHR) Funding Decisions Database (https://cihr-irsc.gc.ca/e/38021. $\underline{\mathrm{html}}$, accessed August 21, 2020). The date, grant size (in $\mathrm{CAD}$ ), principal investigator (PI), and recipient institution were recorded for each grant.

\section{Statistical Analysis}

Descriptive and comparative statistical analyses were performed using Prism 8 (GraphPad Software ${ }^{\circledR}$, La Jolla California, USA). Student's t-tests were performed to compare non-parametric data between the two groups, and Kruskal-Wallis H-tests were performed to compare non-parametric data between multiple groups. Dunn's Multiple Comparison Tests were used post-hoc where appropriate. As done by similar studies in the past, sexbased research metrics were corrected by academic rank using a two-tailed analysis of variance (ANOVA). ${ }^{9,13}$
Pearson's coefficients were used for correlative tests. Statistical significance is defined as $\mathrm{p}<0.05$.

\section{Results}

A total of 759 academic ophthalmologists and 120 vision scientists were identified from departmental faculty lists. Of these, 686 ophthalmologists (90.4\%) and 119 vision scientists $(99.2 \%)$ had online bibliometric profiles featuring an h-index and m-quotient. Average h-indices were $7.42 \pm 7.98$ (median 5.00, range 0-64.00) for academic ophthalmologists and $23.78 \pm 15.25$ (median 21.00, range 0-106.00) for vision scientists. Table 1 describes the mean h-index and m-quotient for ophthalmologists and vision scientists stratified by sex, degree, academic appointment, fellowship training and clinical subspecialty. Average H-indices were $7.89 \pm 8.01$ for male ophthalmologists and $6.21 \pm 7.78$ for female ophthalmologists. For vision scientists, the average $\mathrm{H}$-indices were $24.87 \pm$ for men and $21.86 \pm 12.22$ for women. These differences were not significant when correcting for academic rank (Figure 1A and B).

\section{Sex-Based Metrics}

Table 2 describes the male-female distribution of ophthalmologists and vision scientists with bibliometric profiles in Canada by academic appointment and institution. On average, $72 \%$ of Canadian academic ophthalmologists were men and $28 \%$ were women. Université Laval and Université de Montréal had the most balanced faculties, with male:female ratios close to 1 .

Canada's cohort of female ophthalmologists is at a younger career stage than males, indicated by their later average first year of publication compared to males (2002.52 \pm 9.62 for women vs $1996.01 \pm 12.07$ for men, $\mathrm{p}<0.001)$. This trend was also observed among vision scientists $(1993.93 \pm 9.61$ for women vs $1989.63 \pm 11.96$ for men, $\mathrm{p}<0.05)$. These results are summarized in Figure 2.

\section{Academic Appointment}

$\mathrm{H}$-indices generally increased with academic appointment (Figure $3 \mathrm{~A}$ and B). Similar trends were seen when comparing m-quotients between academic ranks of ophthalmologists and vision scientists (Figure 3C and D).

Of Canada's 28 past or present Chairs of Ophthalmology, 24 (86\%) were male and $4(14 \%)$ were female (Table 2). Eighteen (64\%) were Professors, 7 (25\%) were Associate Professors, and 3 (11\%) were 
A

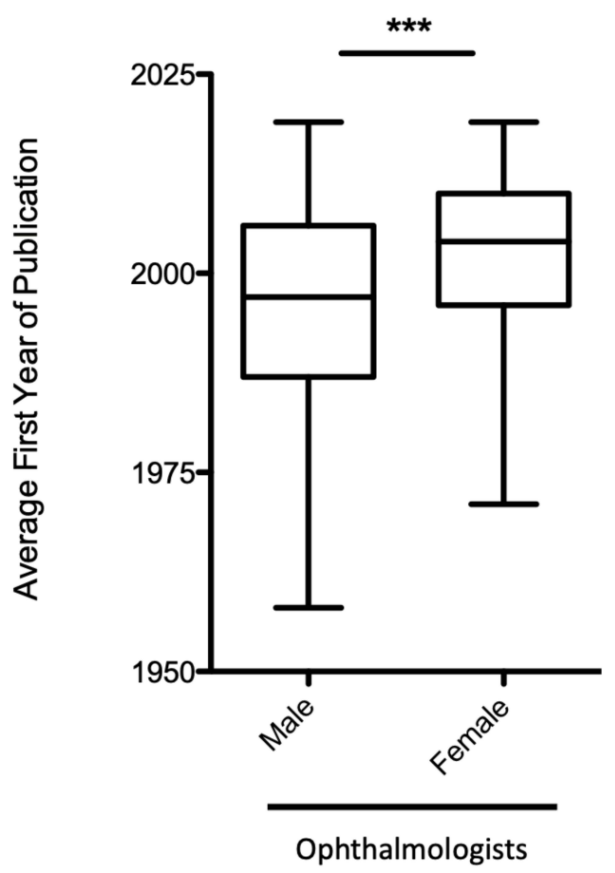

B

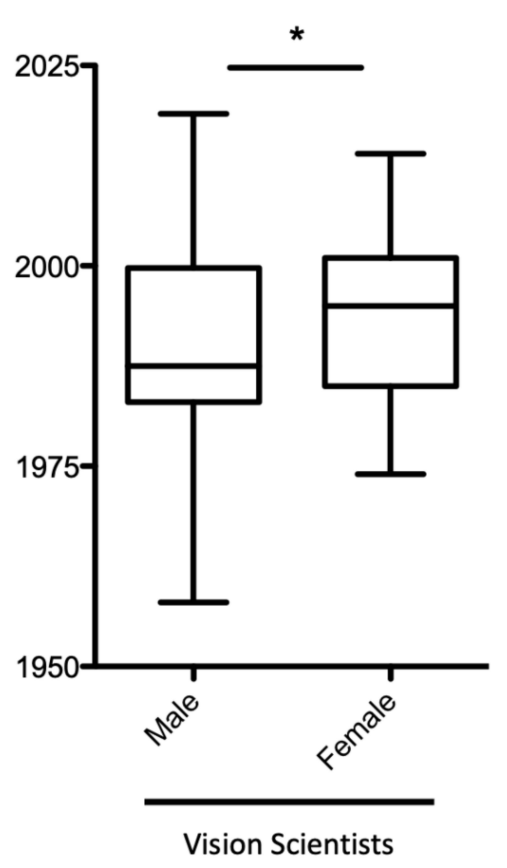

Figure 2 Average year of first publication for $(\mathbf{A})$ ophthalmologists and $(\mathbf{B})$ vision scientists, stratified by sex $(* * * P<0.00$ I, $* \mathrm{P}<0.05$, Student's $t$-test).

Assistant Professors. Twenty-three (82\%) were MDs and 5 were $\mathrm{MD} / \mathrm{PhDs}(18 \%)$.

\section{Educational Background}

For ophthalmologists, $\mathrm{MD} / \mathrm{PhDs}$ had higher average $\mathrm{H}$-indices, m-quotients, and citations than MDs alone (H-index means $17.33 \pm 11.13$ vs $6.95 \pm 7.51$, p < 0.001). Similarly, for vision scientists, $\mathrm{PhDs}$ and $\mathrm{MD} /$ $\mathrm{PhDs}$ had higher H-indices than MDs alone. H-indices between these groups are shown in Figure 4.

There was also a statistically significant increase in $\mathrm{H}$-index, m-quotient, and number of citations with increasing number of fellowships ( $<<0.0001$; Table 1$)$.

In Canadian academic ophthalmology departments, the most common areas of focus included Comprehensive Ophthalmology (26\%), Retina (18\%), and Glaucoma and Cornea/External Disease (14\% each). Figure 5A demonstrates the frequency of the various subspecialties in academic universities. The least represented specialties, including Ocular Genetics (1\%), Ocular Oncology (3\%), and Ocular Pathology (1\%) had the highest $\mathrm{H}$-indices (means $24.10 \pm 15.24,15.13 \pm 17.38$ and $10.22 \pm 10.21$, respectively). Average h-indices by subspecialty are highlighted in Figure 5B.

\section{Institution}

Average $\mathrm{H}$-indices were analyzed by institution for clinicians and vision scientists separately (Figure 6). In clinical ophthalmology research, the top three departments with the highest average $\mathrm{H}$-indices were Western University, the University of Toronto, and Dalhousie University. For basic science research, the University of British Columbia, McGill University, and the University of Toronto had the highest average $\mathrm{H}$-indices. Figure 6 compares the impact of Canadian ophthalmologists and vision scientists against their American counterparts.

Western University, the University of Toronto, and Dalhousie University had the highest impact on a sustained basis as indicated by average m-quotient (Figure 7A). There was no correlation between the sustained productivity of each institution with the career longevity of its faculty members (Figure $7 \mathrm{C}, \mathrm{R}^{2}=0.0$, $\mathrm{p}=0.83$ ).

\section{Canadian Institutes of Health Research (ClHR) Funding}

Figure 8 depicts trends in CIHR funding awarded to each institution between 2008 and 2020. The institutions 


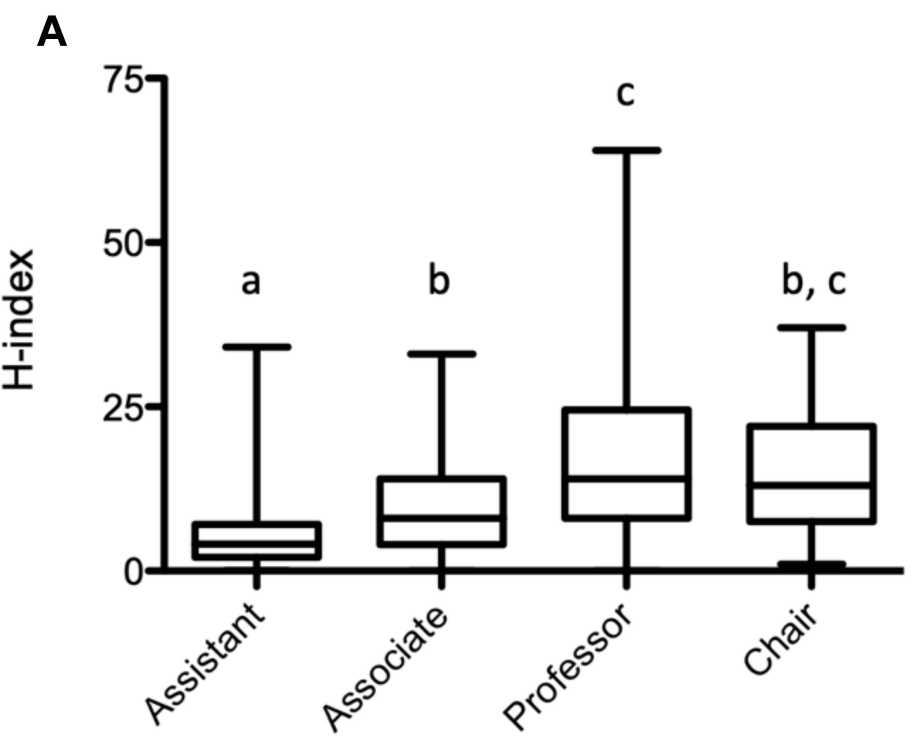

B
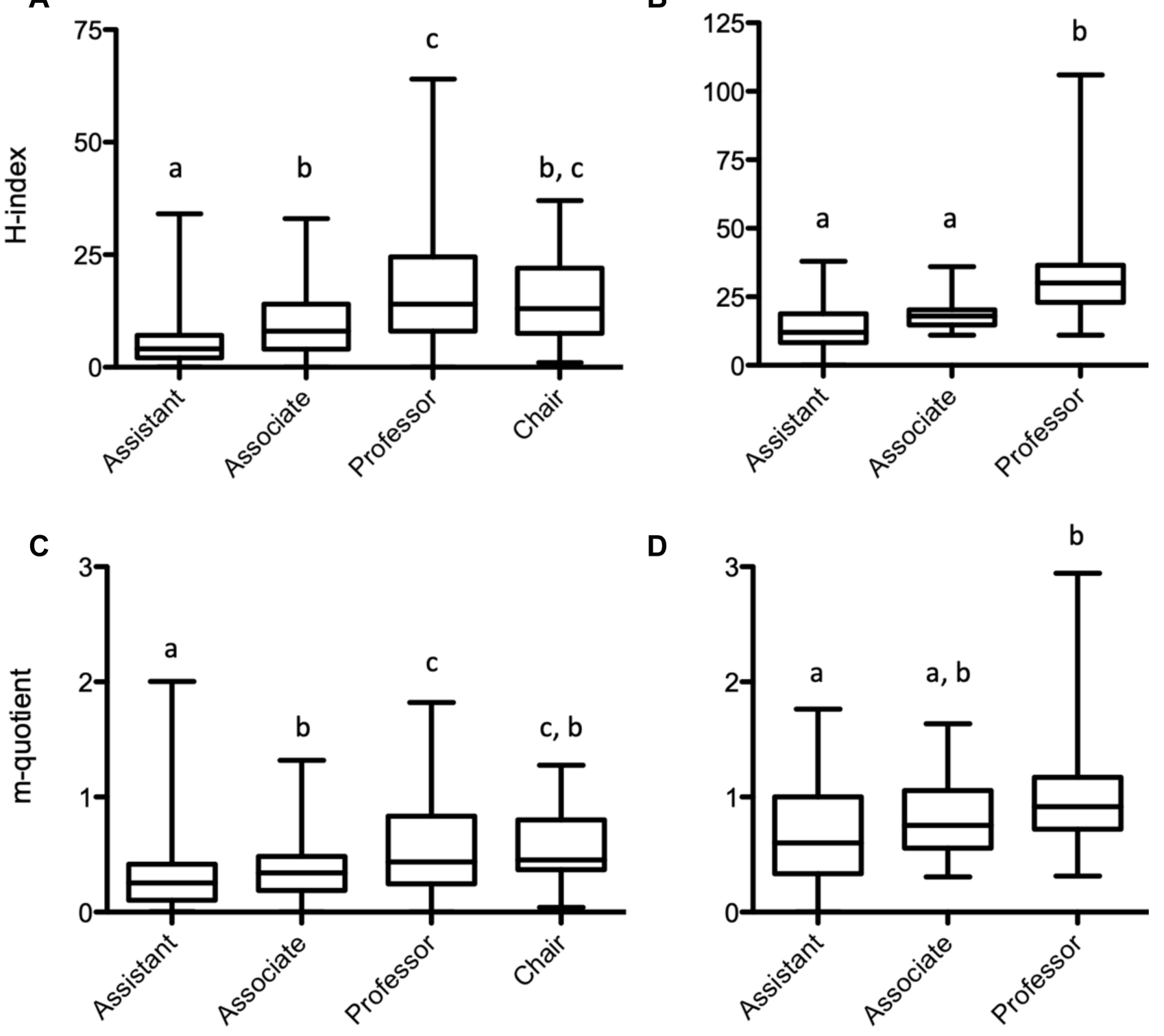

Figure 3 Average $\mathrm{H}$-indices by rank for (A) ophthalmologists and (B) vision scientists; and average $\mathrm{m}$-quotients by rank for (C) ophthalmologists and (D) vision scientists. Groups with the same letter were not significantly different from one another $(p<0.05$, Kruskal Wallis test).

with the greatest CIHR funding between 2008 and 2020 were the University of British Columbia (\$8.3 M), Université de Montréal (\$6.2 M) and McGill University $(\$ 4.9 \mathrm{M})$. There was no correlation between average institutional $\mathrm{H}$-index and total CIHR funding $\left(\mathrm{R}^{2}=0.02, \mathrm{p}=0.72\right)$.

\section{Discussion}

Bibliometrics are a helpful objective indicator of academic impact and are increasingly being adopted in the academic promotion process. The H-index has been increasingly favoured as a measure of productivity due to its elegant method of balancing publication quantity and quality - and in the case of the m-quotient, assessing consistent productivity over time. $^{15-19}$

Of Canada's 1246 ophthalmologists, ${ }^{20} 686$ (55\%) were affiliated with academic departments and had online bibliometric profiles. This is a surprisingly high number of academic clinicians. In comparison, we estimate from International Council of Ophthalmology data that only $15 \%$ of American ophthalmologists have academic practices. $^{9,21}$ In reality, many of these Canadian academic ophthalmologists work peripherally with academic centres and spend much of their time in private practice. These nuances around academic affiliation in Canada may have deflated averages of scholarly productivity or skewed 
A

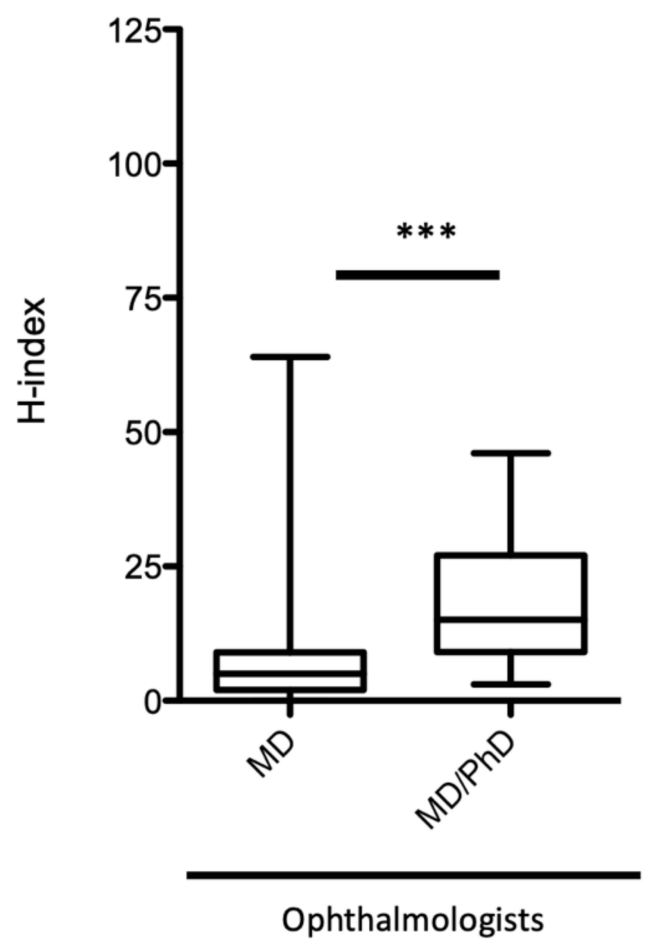

B

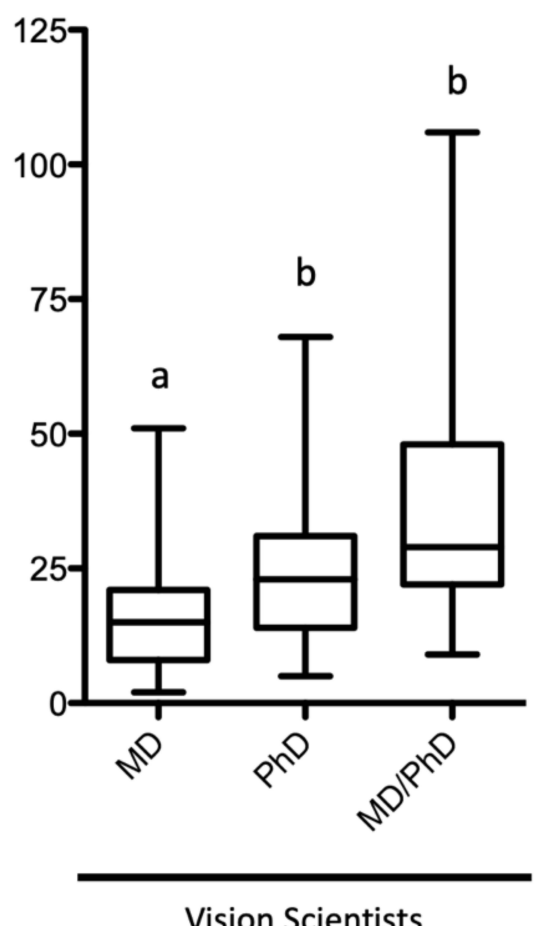

Figure 4 Average $\mathrm{H}$-index by degree for $(\mathbf{A})$ ophthalmologists and $(\mathbf{B})$ vision scientists. $(* * * \mathrm{P}<0.000 \mathrm{I}$, Student's $t$-test. Groups with the same letter were not significantly different from one another $(p<0.05$, Kruskal-Wallis test $)$ ).

demographic data for departments in this study. The growing dichotomy between clinician-scientists and clinicianeducators in modern departments may also contribute to variations in averages of scholarly productivity.

Twenty-eight percent of academic ophthalmologists in Canada are women, a rate similar to that seen in the United States, $\sim 30 \%{ }^{9,13}$ This figure falls short of overall Canadian averages, with women comprising $41 \%$ of the overall medical workforce and $36.2 \%$ of specialists in 2017. ${ }^{22}$ Women were also underrepresented at higher levels of appointment. In this study, women represented only $21 \%$ of Canadian Professors of Ophthalmology and $14 \%$ of program Chairs. Notably, the ophthalmology faculties at Université de Montréal and Université Laval were equally balanced in sex. Veilleux et al observed a similar trend at the Université de Montréal and Université Laval in their neurosurgery faculties and attributed this to cultures around staff recruitment at these institutions. $^{23}$ However, leadership among Canadian ophthalmology programs may be trending towards greater representation of women, considering that 4 out of Canada's 15 centres (26\%) currently have female Chairs.
Supporting this notion, women in Canadian academic ophthalmology departments were on average 6 years earlier in their career stage than men as indicated by first year of publication. Corrected for career stage and academic rank, there were no differences in scholarly productivity between male and female ophthalmologists. Further confirming this trend, a sub-analysis of the average $\mathrm{H}$-indices between male and female ophthalmologists in their first 10 and 15 years of professional activity did not show any significant differences $(\mathrm{p}>$ 0.05 for both). Other studies have similarly found no significant differences in scholarly productivity between male and female academic ophthalmologists in the United States. ${ }^{9,13}$

Our study found that $\mathrm{H}$-index and m-quotient increased with academic appointment, $\mathrm{MD} / \mathrm{PhD}$ designation and further training. Similar trends have been observed in the United States. ${ }^{9,11-13,17,24,25}$ These results indicate that Professors, Associate Professors, MD/ $\mathrm{PhDs}$, and fellowship-trained ophthalmologists generally produce higher impact work, and importantly, do so consistently over the duration of their careers. Of note, 
A

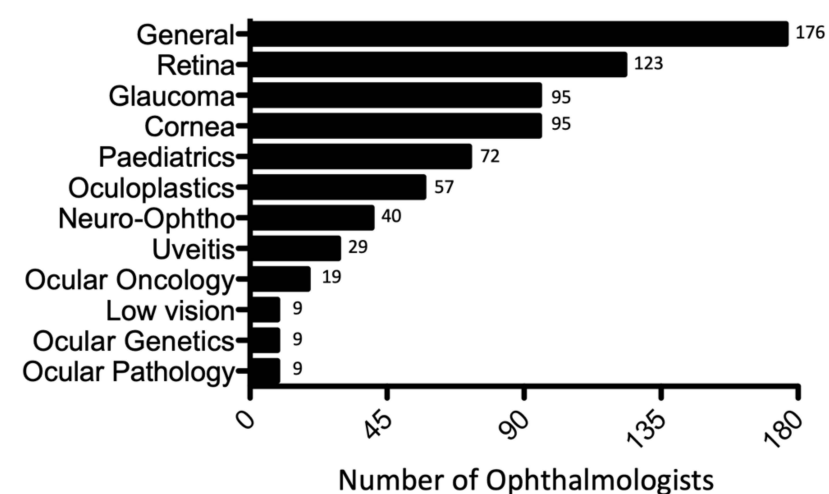

B

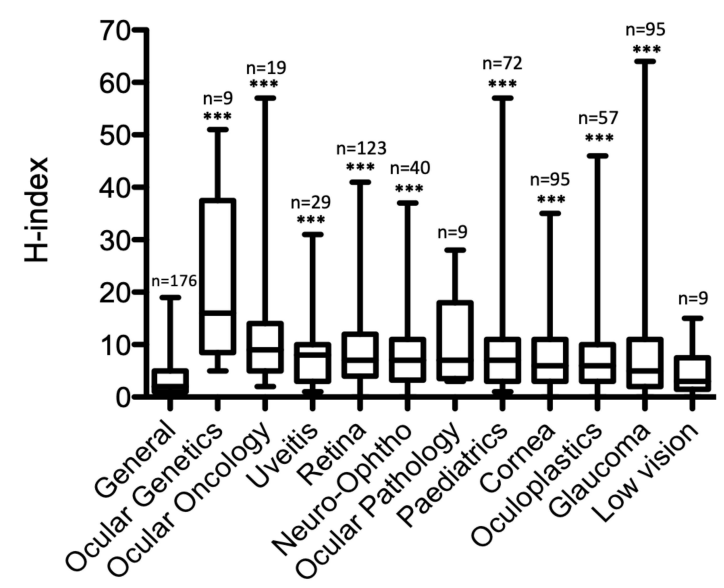

Figure 5 (A) The number of ophthalmologists per subspecialty in Canada, and (B) average $\mathrm{H}$-indices of members in each subspeciality $\left({ }^{*} * * \mathrm{P}<0.001\right.$ against General/ Comprehensive, Dunn's Multiple Comparison Tests).

however, many $\mathrm{MD} / \mathrm{PhD}$ clinicians focused their PhDs on general science topics, such as biology, chemistry, and physics. Thus, the $\mathrm{H}$-index of $\mathrm{MD} / \mathrm{PhD}$ clinicians may be inflated by $\mathrm{PhD}$ publications in other more widely read fields.

Measuring departmental achievement based on the contributions of its members has been done in other specialties $^{9,26}$ and may be helpful for program chairs to evaluate their programs, orient recruitment strategies and direct funding procurement initiatives. Compared to other scientific and medical disciplines, ophthalmology researchers typically have a lower $\mathrm{H}$-index due to the profession's smaller community and readership. ${ }^{27}$ In contrast, researchers in ocular genetics, pathology and oncology had relatively high $\mathrm{H}$-indices, a trend that corroborates the results of other American studies. ${ }^{9,12}$ Thiessen et al believed that this trend represented the effect of a few extremely productive ophthalmologists in relatively small, academically oriented fields. ${ }^{9}$ However, these fields are also some of the most medically generalizable, and as such papers in these areas are often published in journals that have a wider readership throughout medicine. This likely also explains why basic science researchers and other specialties have higher metrics than clinical ophthalmologists.

Canadian departments had lower H-indices than their American counterparts, a trend previously identified in other specialties, including general surgery, ${ }^{17,28} \quad$ neurosurgery, ${ }^{26,28,29}$ plastic surgery, ${ }^{15,17,28,30,31}$ vascular surgery, ${ }^{17,28}$ cardiothoracic surgery, ${ }^{17,28,32}$ otolaryngology ${ }^{18,33}$ and physiatry. ${ }^{34-36}$ American centres may have higher indices of impact for several reasons. Canadian centres are fewer in number and likely to see higher patient volumes, requiring academic clinicians to focus more of their time clinically than their American counterparts. American centres may also have more resources for research, including academic time, funding, and greater numbers of trainees who could assist with research initiatives.

The m-quotient is indicative of sustained publication impact over time and is useful when comparing younger researchers to their more seasoned counterparts. Université Laval, the University of Saskatchewan, and McMaster University had the youngest faculties as indicated by their members' average years of first publication. In contrast, McGill University, and the Universities of British Columbia (UBC) and Toronto had the most seasoned faculty. Notably, Université Laval, Queen's University, and the Université de Montréal (UdeM) had younger staff with sustained levels of research productivity, as indicated by m-quotients (Figure 6C). However, the m-quotients of junior staff may be skewed by recent high impact work done during fellowship.

Funding by the Canadian Institutes of Health Research (CIHR) was greatest at some of the larger Canadian schools, including UBC, UdeM, and McGill University. Similar results were observed in a census of Canadian ophthalmology programs in 2010..$^{5}$ Our results indicate that Western University, Dalhousie University, and the University of Toronto may have employed these resources most efficiently, as these schools had among the lowest funding per faculty member and higher average $\mathrm{H}$-indices per dollars of 
A

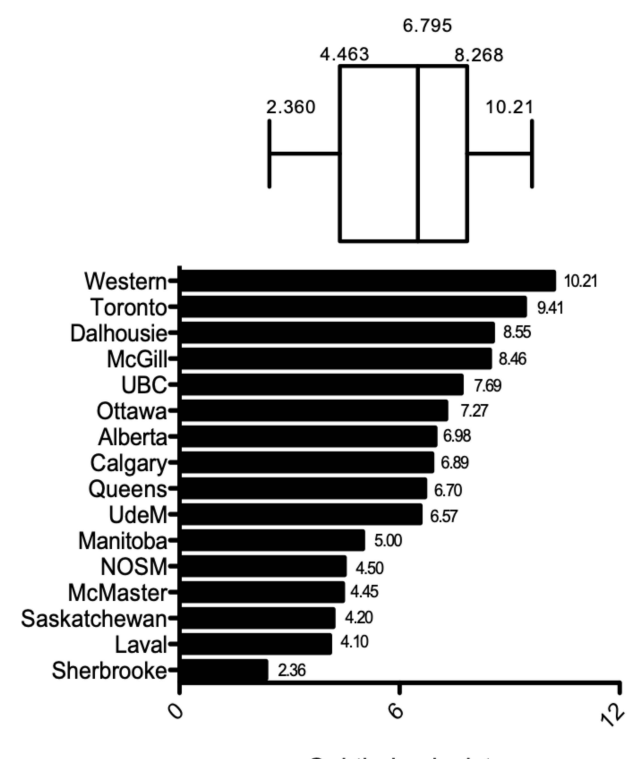

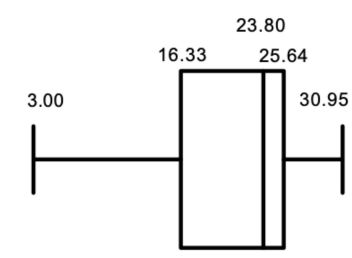

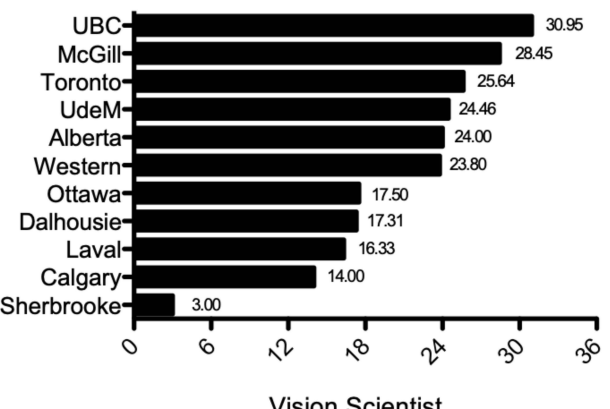

Vision Scientist

Average $\mathrm{H}$-index

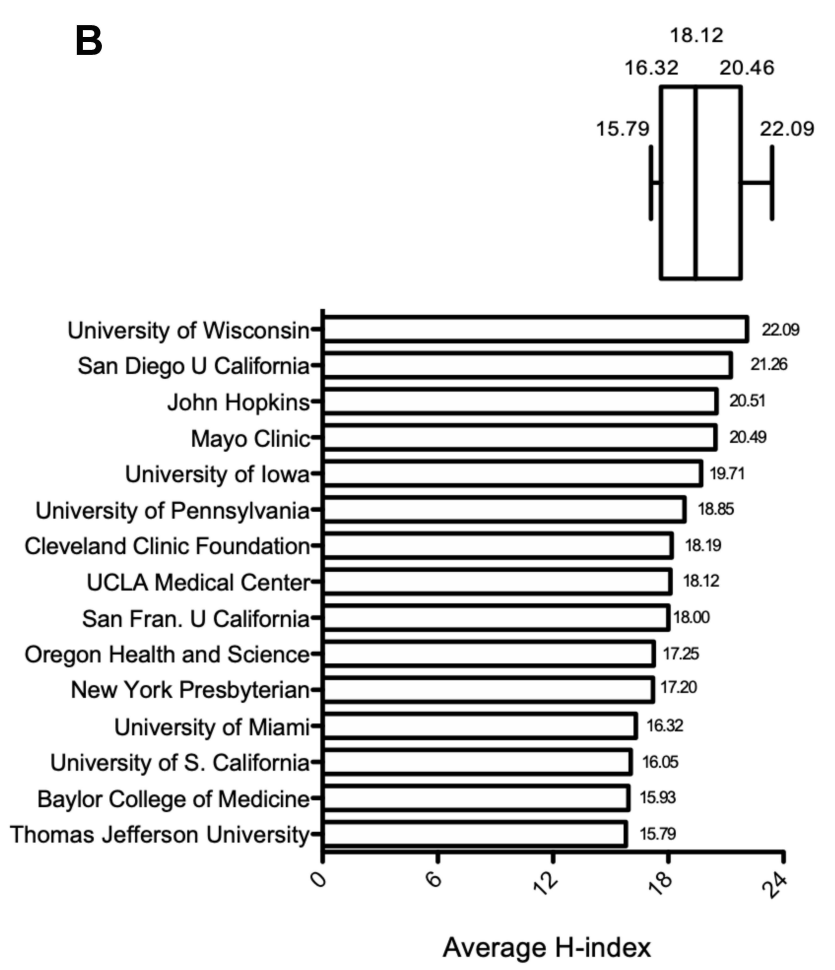

Figure 6 Comparison of average H-indices for (A) Canadian researchers (2020), and (B) American ophthalmologists (2016).9.

CIHR funding. There was no correlation between CIHR funding and average institutional H-index, suggesting that the average quality of publications is similar across schools despite funding differences. However, the CIHR is only one potential source of funding for Canadian departments. Larger departments often have other significant sources of funding that smaller institutions may not have access to.

While the sum of H-indices may highlight the overall impact of large faculties, averages indicate the efficiency of departments and may be better benchmarks for 
A
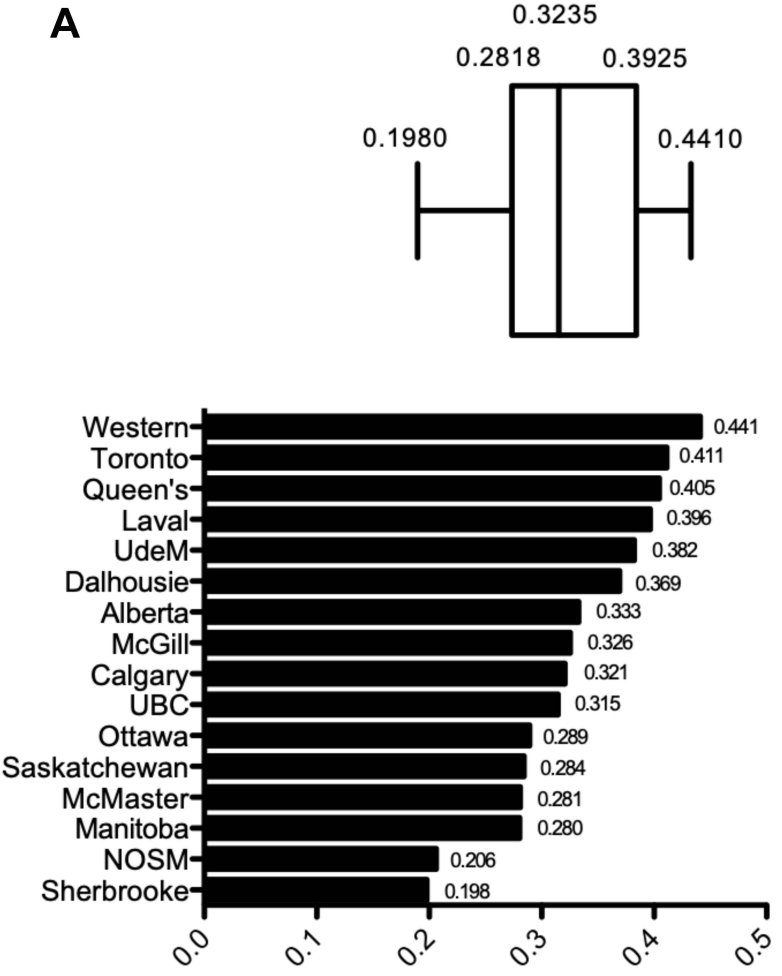

Average m-quotient
B
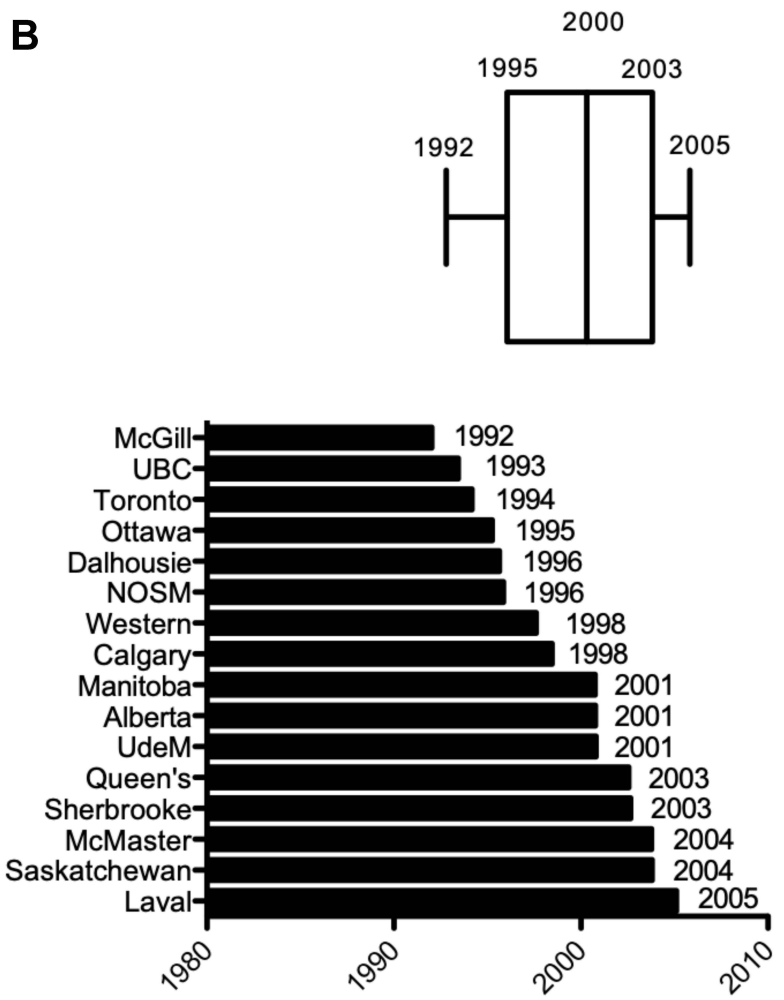

Average First Year of Publication by School Researcher

C

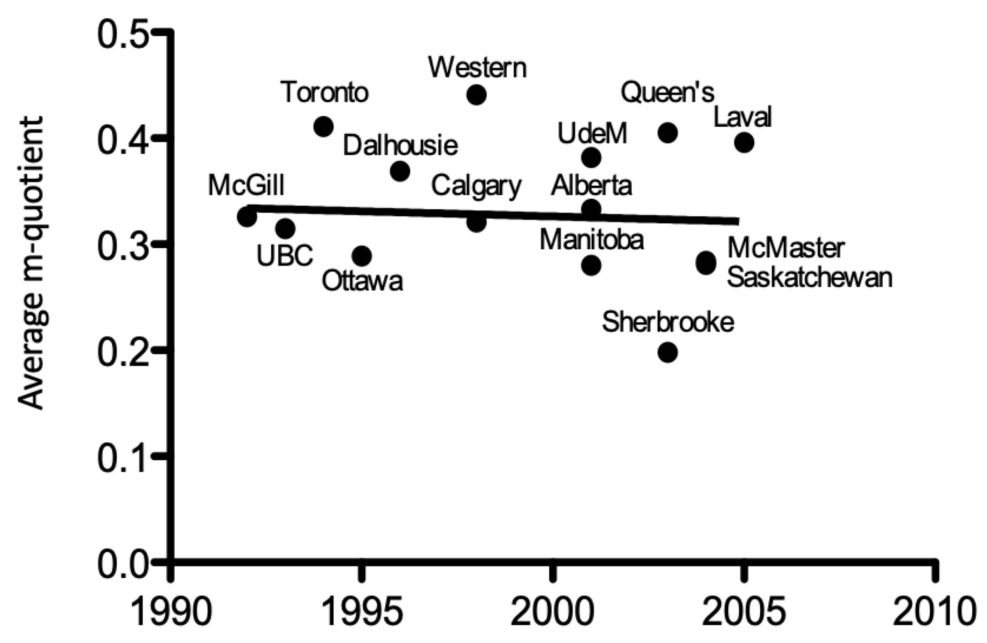

Average First Year of Publication by School Researcher

Figure 7 (A) Average m-quotients by institution, (B) career longevity of institutional faculty members as indicated by average first year of publication, and (C) research productivity as a function of career longevity.

smaller institutions. ${ }^{9}$ However, in small institutions, a few highly productive faculty members may unduly skew averages as well. Other limitations of using the $\mathrm{H}$-index include the positive correlation of $\mathrm{H}$-index with career length due to accumulating citation count, and also that highly prolific papers may not be adequately accounted for. ${ }^{19}$ Also, H-indices may be inflated by coauthorship regardless of the extent of their contribution. ${ }^{27}$ Our study avoided pitfalls of other papers in the literature by excluding self-citations. 
A
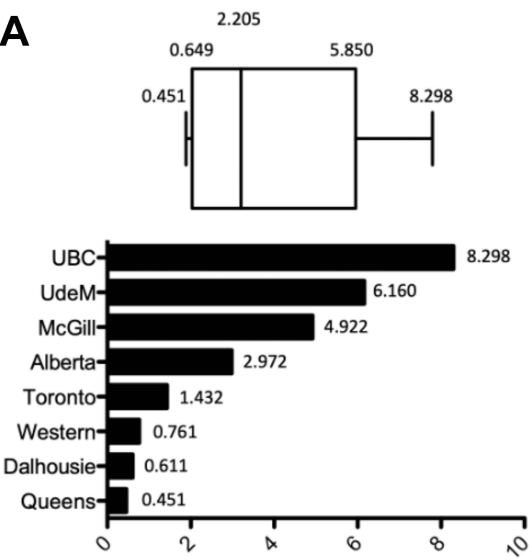

CIHR Funding (Millions of CAD)

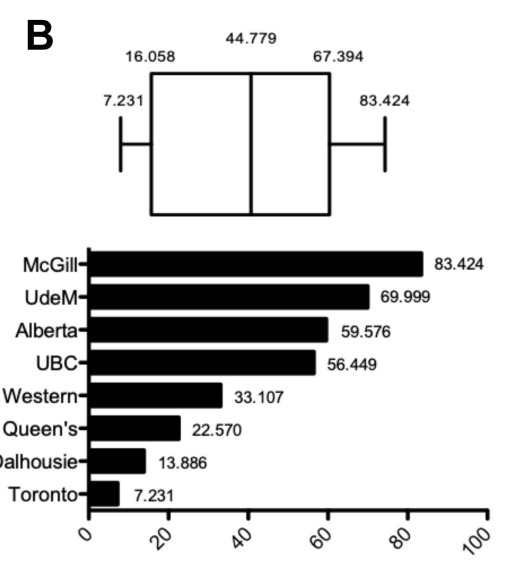

CIHR Funding per Number of Faculty (Thousands of CAD)
C

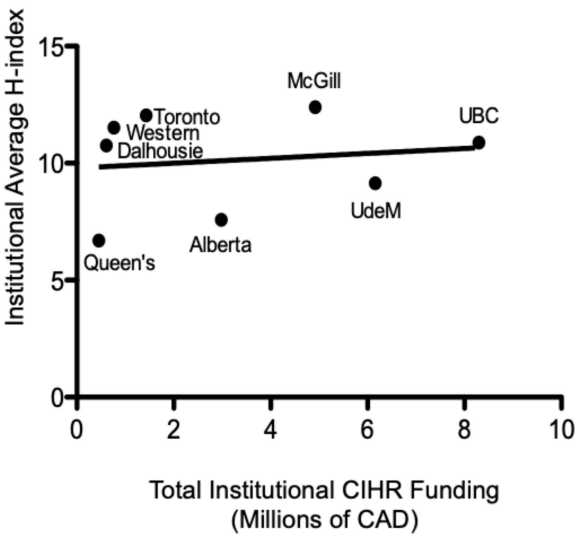

Figure 8 Canadian Institutes of Health Research (CIHR) funding: (A) total funding per school, (B) institutional funding per number of faculty, and (C) average institutional $\mathrm{H}$-index as a function of CIHR funding.

However, like other studies, the exclusion of faculty without online bibliometric profiles $(n=74)$ may have resulted in unintentional errors in the analysis. Finally, this study does not account for other important ways in which clinicians and scientists disseminate new knowledge, including through conferences, presentations and over social media.

The H-index and m-quotient are useful indicators of scholarly productivity. This paper summarizes these metrics for Canadian academic ophthalmologists and vision scientists and highlights cogent workforce trends. Author impact increased with academic appointment, subspecialty training and $\mathrm{MD} / \mathrm{PhD}$ designation. There were no differences in impact between sexes, although women were underrepresented at higher levels of appointment. Considerable variation was seen in CIHR funding between schools; however, CIHR funding was not associated with averages of scholarly impact. We hope that the above results will help guide the continuing development of robust ophthalmology and vision science programs in Canada.

\section{Disclosure}

The authors have no conflicts of interest to disclose.

\section{References}

1. Svider PF, Lopez SA, Husain Q, Bhagat N, Eloy JA, Langer PD. The association between scholarly impact and national institutes of health funding in ophthalmology. Ophthalmology. 2014;121(1):423-428. doi:10.1016/j.ophtha.2013.08.009

2. Smith M. Research in residency: do research curricula impact post-residency practice? Fam Med. 2005;37(5):322-327.
3. Mullen SJ, Sabri K. Role of journal club in Canadian ophthalmology residency training: a national survey of program directors. Can J Ophthalmol. 2016;51(3):226-231. doi:10.1016/j.jcjo.2016.04.003

4. Beasley BW, Wright SM, Cofrancesco J, Babbott SF, Thomas PA, Bass EB. Promotion criteria for clinician-educators in the United States and Canada. A survey of promotion committee chairpersons. J Am Med Assoc. 1997;278(9):723-728. doi:10.1001/jama.1997.03 550090047031

5. Schlenker MB, Manalo E, Wong AMF. Research productivity of Canadian ophthalmology departments in top 10 ophthalmology and vision science journals from 2001 to 2010. Can J Ophthalmol. 2013;48(1):46-55. doi:10.1016/j.jcjo.2012.10.001

6. Micieli A, Micieli JA, Smith AF. Analysis of the publication volume of Canadian ophthalmology departments from 2005 to 2009: a systematic review of the literature. Can J Ophthalmol. 2011;46 (1):66-71. doi:10.3129/i10-113

7. Ball P. Achievement index climbs the ranks. Nature. 2007;448 (7155):737. doi:10.1038/448737a

8. Hirsch JE. An index to quantify an individual's scientific research output. Proc Natl Acad Sci USA. 2005;102(46):16569-16572. doi:10.1073/pnas.0507655102

9. Thiessen C, Venable G, Ridenhour N, Kerr N. Publication Productivity for Academic Ophthalmologists and Academic Ophthalmology Departments in the United States: an Analytical Report. J Clin Acad Ophthalmol. 2016;08(01):e19-e29. doi:10.10 55/s-0036-1581111

10. Sweileh WM, Al-Jabi SW, Shanti YI, Sawalha AF. Contribution of Arab researchers to ophthalmology: a bibliometric and comparative analysis. Springerplus. 2011. doi:10.1186/s40064-015-0806-0

11. Dotan G, Qureshi HM, Gaton DD. Chairs of United States academic ophthalmology departments: a descriptive analysis and trends. Am $J$ Ophthalmol. 2018;196:26-33. doi:10.1016/j.ajo.2018.08.016

12. Huang G, Fang CH, Lopez SA, Bhagat N, Langer PD, Eloy JA. Impact of fellowship training on research productivity in academic ophthalmology. J Surg Educ. 2015;72(3):410-417. doi:10.1016/j. jsurg.2014.10.010

13. Lopez SA, Svider PF, Misra P, Bhagat N, Langer PD, Eloy JA. Gender differences in promotion and scholarly impact: an analysis of 1460 academic ophthalmologists. J Surg Educ. 2014;71 (6):851-859. doi:10.1016/j.jsurg.2014.03.015

14. Svider PF, D'Aguillo CM, White PE, et al. Gender differences in successful national institutes of health funding in ophthalmology. J Surg Educ. 2014;71(5):680-688. doi:10.1016/j.jsurg.2014.01.020 
15. Therattil PJ, Hoppe IC, Granick MS, Lee ES. Application of the h-index in academic plastic surgery. Ann Plast Surg. 2016;76 (5):545-549. doi:10.1097/SAP.0000000000000382

16. Bastian S, Ippolito JA, Lopez SA, Eloy JA, Beebe KS. The use of the h-index in academic orthopaedic surgery. J Bone Jt Surg. 2017;99(4): e14. doi:10.2106/JBJS.15.01354

17. Ashfaq A, Kalagara R, Wasif N. H-index and academic rank in general surgery and surgical specialties in the United States. J Surg Res. 2018;229:108-113. doi:10.1016/j.jss.2018.03.059

18. Svider PF, Choudhry ZA, Choudhry OJ, Baredes S, Liu JK, Eloy JA. The use of the h-index in academic otolaryngology. Laryngoscope. 2013;123(1):103-106. doi:10.1002/lary.23569

19. Lee J, Kraus KL, Couldwell WT. Use of the $\mathrm{h}$ index in neurosurgery. J Neurosurg. 2009;111(2):387-392. doi:10.3171/2008.10.JNS08978

20. Canadian Medical Association. Ophthalmology Profile. Ottawa, ON: CMA; 2019:6.

21. Resnikoff S, Felch W, Gauthier T-M, Spivey B. The number of ophthalmologists in practice and training worldwide: a growing gap despite more than 200000 practitioners. Br J Ophthalmol. 2012;96. doi:10.1136/bjophthalmol-2011-301378/content/early/recent

22. Canadian Institute for Health Information. Physicians in Canada, 2017. Ottawa, ON: CIHI; 2019:17.

23. Veilleux C, Samuel N, Yan H, et al. Cross-sectional analysis of women in neurosurgery: a Canadian perspective. Neurosurg Focus. 2021;50(3):1-7. doi:10.3171/2020.12.FOCUS20959

24. Rezek I, McDonald RJ, Kallmes DF. Is the h-index predictive of greater nih funding success among academic radiologists? Acad Radiol. 2011;18(11):1337-1340. doi:10.1016/j.acra.2011.06.017

25 . Elliott ST, Lee ES. Surgical resident research productivity over 16 years. J Surg Res. 2009;153(1):148-151. doi:10.1016/j.jss.2008.03.029

26. Khan NR, Thompson CJ, Taylor DR, et al. An analysis of publication productivity for 1225 academic neurosurgeons and 99 departments in the United States. J Neurosurg. 2014;120(3):746-755. doi:10.3171/ 2013.11.JNS131708

27. Svider PF, Pashkova AA, Choudhry Z, et al. Comparison of scholarly impact among surgical specialties: an examination of 2429 academic surgeons. Laryngoscope. 2013;123(4):884-889. doi:10.1002/lary.23951
28. Wang H, Chu MWA, Dubois L. Variability in research productivity among Canadian surgical specialties. Can J Surg. 2021;64(1):E76E83. doi:10.1503/CJS.016319

29. Ponce FA, Lozano AM. Academic impact and rankings of American and Canadian neurosurgical departments as assessed using the $\mathrm{h}$ index. J Neurosurg. 2010;113(3):447-457. doi:10.3171/2010.3.JNS1 032

30. Hu J, Gholami A, Stone N, Bartoszko J, Thoma A. An evaluation of h-index as a measure of research productivity among Canadian academic plastic surgeons. Plast Surg. 2018;26(1):5-10. doi:10.1177/ 2292550317749508

31. Edalatpour A, Nkana ZH, Bentz ML, Afifi AM. Academic productivity in plastic surgery: a comparison of us and international medical graduates. J Craniofac Surg. 2020;31(8):2136-2138. doi:10.1097/ SCS.0000000000007040

32. Rosati CM, Vardas PN, Gaudino M, et al. Academic productivity of US cardiothoracic surgical centers. J Card Surg. 2016;31(7): 423-428. doi:10.1111/jocs. 12773

33. Fu T, Wu V, Campisi P, Witterick IJ, Chan Y. Academic benchmarks for leaders in otolaryngology - head \& neck surgery: a Canadian perspective. J Otolaryngol - Head Neck Surg. 2020;49(1):1-7. doi:10.1186/s40463-020-00419-4

34. Yang HY, Rhee G, Xuan L, Silver JK, Jalal S, Khosa F. Analysis of $\mathrm{H}$-index in assessing gender differences in academic rank and leadership in physical medicine and rehabilitation in the United States and Canada. Am J Phys Med Rehabil. 2019;98(6):479-483. doi:10.1097/ PHM.0000000000001129

35. Gaught AMH, Cleveland CA, Hill JJ. Publish or Perish? Am J Phys Med Rehabil. 2013;92(8):710-714. doi:10.1097/PHM.0b013e3182 876197

36. Bateman EA, Teasell R. Publish or Perish. Am J Phys Med Rehabil. 2019;98(12):1142-1146. doi:10.1097/PHM.0000000000001299
Clinical Ophthalmology

\section{Publish your work in this journal}

Clinical Ophthalmology is an international, peer-reviewed journal covering all subspecialties within ophthalmology. Key topics include: Optometry; Visual science; Pharmacology and drug therapy in eye diseases; Basic Sciences; Primary and Secondary eye care; Patient Safety and Quality of Care Improvements. This journal is indexed on PubMed
Dovepress

Central and CAS, and is the official journal of The Society of Clinical Ophthalmology (SCO). The manuscript management system is completely online and includes a very quick and fair peer-review system, which is all easy to use. Visit http://www.dovepress.com/ testimonials.php to read real quotes from published authors. 